\title{
Cushing's syndrome with suppression of the hypothalamic-pituitary-adrenal axis after intra-articular steroid injections
}

\author{
M M O'SULLIVAN, W R RUMFELD, M K JONES, AND B D WILLIAMS \\ From the Departments of Rheumatology and Medicine, University Hospital of Wales, Heath Park, Cardiff \\ CF4 $4 X W$
}

SUMmARY A case of Cushing's syndrome after long term intra-articular corticosteroid injections is described. Prolonged suppression of the hypothalamic-pituitary-adrenal axis occurred as assessed by an insulin tolerance test 11 weeks after the last intra-articular injection. Replacement steroid therapy was required.

Key words: intra-articular corticosteroids.

Intra-articular corticosteroid injections for rheumatic conditions were first introduced by Hollander in 1951. Hydrocortisone acetate was the first intraarticular preparation used but has been replaced by a number of synthetic steroid derivatives whose duration of action is much longer. Studies comparing the relative efficacy of these agents ${ }^{12}$ have shown that the duration of response correlates inversely with the solubility of the preparation in water, the least soluble triamcinolone hexacetonide having the longest action. ${ }^{3-5}$ Steroid absorbed from the synovial cavity induces systemic effects, including diminished joint swelling at sites distant from the injected joint ${ }^{6}$ and transient eosinopenia. ${ }^{7}$ Estimation of plasma levels of synthetic steroids after intraarticular injection has confirmed their systemic absorption. ${ }^{8}$ A single report records possible iatrogenic Cushing's syndrome after repeated local steroid injections in a patient with rheumatoid arthritis. ${ }^{9}$

In this communication we report a patient with rheumatoid arthritis who developed iatrogenic Cushing's syndrome with prolonged suppression of the hypothalamic-pituitary-adrenal axis after long

Accepted for publication 28 February 1985.

Correspondence to Dr M M O'Sullivan, Department of Rheumatology, University Hospital of Wales, Heath Park, Cardiff CF4 $4 \mathrm{XW}$. term administration of intra-articular triamcinolone hexacetonide.

\section{Case report}

A 59-year-old male, who developed seropositive rheumatoid arthritis in 1976, was referred to our clinic in May 1984 for investigation of muscle weakness. Early on in the course of his disease he had received treatment with Myocrisin and penicillamine, but both drugs were discontinued because of the development of side effects. Rheumatoid involvement of his shoulders and knees was particularly severe, and for eight years he was given intraarticular injections of triamcinolone hexacetonide $300 \mathrm{mg}$ divided equally between the four joints and given at eight-weekly intervals. For several years his joint symptoms were well controlled by the intraarticular injections, but in the three years before attendance at our clinic the nature of his symptoms changed. His appetite was poor and he became easily tired and lethargic. These symptoms appeared five weeks after steroid injection but disappeared within hours of the next intra-articular injection.

The patient is shown in Fig. 1. He had truncal obesity with pronounced buffalo hump. On examination he had thin skin and bruising with general and palmar crease pigmentation. Muscle wasting 


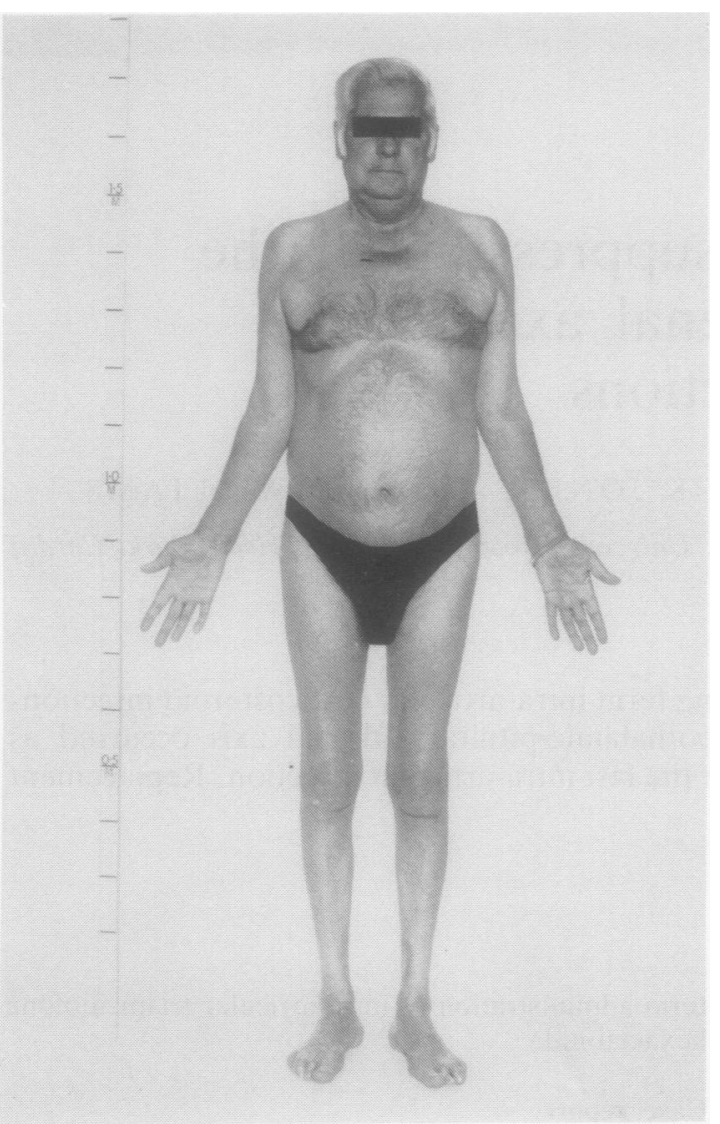

Fig. 1 The patient.

and weakness of his shoulder girdles and pelvic girdle muscles was evident, though the weakness at the shoulder girdles could be attributed in part to the limited range of movement present at these joints. The laboratory investigations were as follows: haemoglobin $14.8 \mathrm{~g} / \mathrm{dl}$, erythrocyte sedimentation rate $84 \mathrm{~mm} / \mathrm{h}$ (Westergren), sodium $138 \mathrm{mmol} / \mathrm{l}$, potassium $4.2 \mathrm{mmol} / \mathrm{l}$, urea $5 \cdot 1 \mathrm{mmol} / \mathrm{l}$, rheumatoid factor titre $1 / 2048$, antinuclear factor negative, blood glucose $8.4 \mathrm{mmol} / \mathrm{l}$, free thyroxine $18 \mathrm{pmol} / \mathrm{l}$ (normal range 8-26 pmol/l), creatine phosphokinase $26 \mathrm{IU} / \mathrm{l}$ (normal range $0-130 \mathrm{IU} / \mathrm{l})$. Skull $\boldsymbol{x}$-ray was normal.

An assessment of his hypothalamic-pituitaryadrenal axis was carried out 11 weeks after the last injection of triamcinolone hexacetonide. The 0900 hour plasma cortisol was less than $28 \mathrm{nmol} / \mathrm{l}$. The plasma cortisol response to $1 \mathrm{mg}$ of Synacthen Depot (tetracosactrin) given at 0900 hours was normal, with a peak value at eight hours of 622 nmol/l (Table 1). Metyrapone $250 \mathrm{mg}$ given two hourly for 72 hours did not produce an increase ino the 24-hour excretion of 17-hydroxycorticosteroids (17-OHCS) (Table 2).

The changes in plasma glucose, prolactin, growthe hormone, and cortisol levels during the insulin tolerance test are shown in Table 3. The fall in plasma glucose was sufficient to produce symptomso of hypoglycaemia. The expected rise in plasmos prolactin occurred, there was some impairment inthe growth hormone response (normal $>20 \mathrm{IU} / \mathrm{l}$ ) and there was no change in the plasma cortiso $\omega_{0}$ levels. After endocrine assessment our patient was? discharged on replacement therapy (prednisone $2 \cdot \frac{5}{5}$ mg twice daily), which abolished his previouse symptoms of lethargy and malaise.

\section{Discussion}

Intra-articular corticosteroid injections are a valuable adjunct in the management of rheumatoid arthritis especially when active disease is confined te a few joints. ${ }^{10}$ At a dose range which varies between? 10 and $40 \mathrm{mg}$ intra-articular injections of triamcino $\vec{\bullet}$ lone hexacetonide generally produce a sustainedo improvement in patient symptoms. Our patient received twice the recommended dose into theo knees and shoulders, and because of a favourables response the injections were continued at eighto weekly intervals for a period of seven years. If became apparent, however, that during the las three years intra-articular steroids were necessary t $\overrightarrow{\vec{D}}$ reverse the general symptoms which had develope as a result of hypothalamic-pituitary-adrenal sup pression.

Table 1 Long Synacthen test $(1 \mathrm{mg}$ Synacthen Depot (tetracosactrin) given at 0900 hours)

\begin{tabular}{|c|c|}
\hline Time (h) & Plasma cortisol (nmol/l) \\
\hline 0 & 102 \\
\hline 6 & 518 \\
\hline 8 & 622 \\
\hline 24 & 584 \\
\hline 48 & 116 \\
\hline
\end{tabular}

Table 2 Metyrapone $250 \mathrm{mg}$ given two hourly for 72 hourse

\begin{tabular}{|c|c|}
\hline & $\begin{array}{l}\text { 17-OHCS excretion } \\
(\mathrm{mg} / 24 \mathrm{~h})\end{array}$ \\
\hline Basal rate & $2 \cdot 8$ \\
\hline Day 1 & $2 \cdot 5$ \\
\hline Day 2 & 0.5 \\
\hline Day 3 & 0.6 \\
\hline
\end{tabular}


Table 3 Insulin tolerance test

\begin{tabular}{|c|c|c|c|c|c|c|c|}
\hline & \multicolumn{7}{|c|}{ Time $(h)$} \\
\hline & -30 & 0 & +15 & +30 & +60 & +90 & +120 \\
\hline Plasma glucose (nmol/l) & $4 \cdot 5$ & $4 \cdot 4$ & $3 \cdot 6$ & $2 \cdot 2$ & $2 \cdot 7$ & $4 \cdot 0$ & $4 \cdot 7$ \\
\hline Plasma prolactin (IU/l) & 396 & 285 & 247 & 246 & 792 & 551 & 500 \\
\hline Plasma growth hormone (IU/l) & $7 \cdot 7$ & $2 \cdot 4$ & $1 \cdot 3$ & $1 \cdot 8$ & $14 \cdot 7$ & $6 \cdot 3$ & 3.9 \\
\hline Plasma cortisol (nmol/l) & $<28$ & $<28$ & $<28$ & $<28$ & $<28$ & $<28$ & $<28$ \\
\hline
\end{tabular}

Transient suppression of the hypothalamicpituitary-adrenal axis, as shown by low 0900 hour plasma cortisol levels, has been reported up to six days after intra-articular steroid injections. ${ }^{11} 12$ In one study of intra-articular injection of methylprednisolone the plasma cortisol was suppressed by $64-81 \% 24$ hours after the injection. This effect of a single dose remained for three days, and the serum cortisol was restored to normal after one week. ${ }^{8}$ Sustained suppression, however, has not previously been reported. In this patient the adrenal suppression was still evident 11 weeks after the last intraarticular steroid injection and was sufficiently severe to be associated with clinical features of cortisol deficiency. The circumstances which led to this suppression were unusual and it is not known whether there would be any significant prolonged adrenal suppression if more conventional doses were given less frequently to patients. The possibility of hypothalamic-pituitary-adrenal axis suppression should, however, be considered in patients who have received repeated intra-articular steroid injections. This is obviously important, as these patients may not respond appropriately to the stress of surgery/trauma or acute medical illness and may require replacement therapy to avoid an adrenal crisis.

\section{References}

1 Balch H W, Gibson J M C, El-Ghorbarey, et al. Repeated corticosteroid injections into knee joints. Rheumatol Rehabil 1977; 11: 137.

2 Hollander $\mathrm{J}$ L. Arthrocentesis and intrasynovial therapy. In: McCarty D J, ed. Arthritis and allied conditions, Philadelphia: Lee and Febiger, 1979; 402-14.

3 Bilka P J. A new-intra-articular steroid. Minn Med 1967; 50: 483.

4 Hollander J L. Jessar R A, Brown R R. A new intra-articular steroid ester with longer effectiveness [Abstract]. Arthritis Rheum 1961; 4: 422.

5 Kendall P H. Triamcinolone hexacetonide. A new corticosteroid for intra-articular therapy. Ann Phys Med 1967; 9: 55.

6 Bywaters E G L, Dixon A St J. Effect of intra-articular injection of cortisone acetate and of hydrocortisone acetate in rheumatoid arthritis. Clin Sci 1953; 12: 15.

7 Ward L E, Mason H L. Systemic effects from hydrocortisone acetate administered intra-articularly to rheumatoid patients. $J$ Lab Clin Med 1953; 42: 961.

8 Armstrong R D, English J, Gibson T, Chakraborty J, Marks V. Serum methylprednisolone levels following intra-articular injection of methylprednisolone acetate. Ann Rheum Dis 1981; 40: $571-4$.

9 Gray R G, Tenenbaum J, Gottlieb N L. Local corticosteroid injection treatment in rheumatic disorders. Semin Arthritis Rheum 1981; 10: 231.

10 Gray R G, Gottlieb N L. Intra-articular corticosteroids - An updated assessment. Clin Orthop 1983; 177: 235-63.

11 Shuster S, Williams I A. Adrenal suppression due to intraarticular corticosteroid therapy. Lancet 1961; ii: 171 .

12 Koehler B E, Urowitz M, Killinger D W. The systemic effects of intra-articular corticosteroid. J Rheumatol 1974; 1: 117. 